\title{
LA CONSTITUCIONALIDAD DEL ARTÍCULO 102 DEL CÓDIGO CIVIL ANTE EL TRIBUNAL CONSTITUCIONAL. COMENTARIO CRÍTICO DEL REQUERIMIENTO DE INAPLICABILIDAD FALLADO EN LA SENTENCIA ROL N ${ }^{\circ} 1.881$, DE 3 DE NOVIEMBRE DE 2011*
}

LUIS A. SiLVA IRARRÁZAVAL ${ }^{* *}$

Santiago, tres de noviembre de dos mil once.

Vistos:

A fojas 1, mediante oficio $N^{\circ}$ 917, recibido en esta Magistratura con fecha 27 de diciembre de 2010, el entonces Presidente de la Corte de Apelaciones de Santiago, Ministro señor Juan Manuel Muñoz Pardo, en la causa sobre recurso de protección caratulada "Peralta Wetzel, César Antonio, y otros con Soto Silva, Juana", Rol N 6.787-2010, requiere, como medida para mejor resolver, un pronunciamiento de este Tribunal Constitucional sobre la aplicabilidad o inaplicabilidad del precepto legal contemplado en el artículo 102 del Código Civil, en el aludido proceso.

El precepto legal cuestionado dispone que:

"El matrimonio es un contrato solemne por el cual un hombre y una mujer se unen actual e indisolublemente, y por toda la vida, con el fin de vivir juntos, de procrear y de auxiliarse mutuamente".

Como antecedentes de la gestión pendiente en que incide el requerimiento de inaplicabilidad deducido, de las piezas principales de los autos remitidas por la Corte de Apelaciones de Santiago se desprende que, el 20 de octubre de 2010, el abogado Jaime Silva Alarcón, actuando en nombre de César Antonio Peralta Wetzel, Hans Harold Arias Montero, Víctor Manuel Arce García, José Miguel Lillo Isla, Stephane Abran y Jorge Manuel Mardones Godoy, interpuso recurso de protección en contra de Juana Soto Silva, oficial civil adjunta del Servicio de Registro Civil e Identificación de Santiago, dando cuenta de que los señores Peralta y Arias, en septiembre de 2010, solicitaron a la recurrida hora para contraer matrimonio, solicitud que les fue denegada por ella aduciendo que la legislación chilena sólo contempla el matrimonio entre un hombre y una

* Colaboración recibida el 22 de noviembre de 2011 y aprobada el 20 de abril de 2012.

** Doctor en Derecho; Profesor de Derecho Constitucional, de la Facultad de Derecho de la Universidad de los Andes. Correo electrónico: Isilva@uandes.cl. 
mujer. Posteriormente, los señores Arce y Lillo le pidieron la convalidación de su matrimonio válidamente celebrado en Argentina y los señores Abran y Mardones le requirieron que se inscribiera su matrimonio válidamente celebrado en Canadá, rechazándose ambas peticiones por la recurrida, quien señaló que sólo podía inscribir matrimonios celebrados entre un hombre y una mujer.

(...)

Y considerando:

\section{ANÁLISIS DEL REPROCHE DE AUTOS}

(...)

Cuarto: Que los recurrentes de protección se hicieron parte en el proceso de inaplicabilidad iniciado por la Corte de Apelaciones de Santiago. De conformidad a lo señalado en las piezas principales de la gestión pendiente en que se plantea la inaplicabilidad y de lo alegado en estrados por los abogados de las partes, resulta que la cuestión sobre la cual debe pronunciarse este sentenciador y que configura su competencia específica para el presente caso, es determinar si la aplicación del artículo 102 del Código Civil en el aludido recurso de protección infringe o no la garantía de igualdad ante la ley, contenida en el artículo 19, $N^{\circ} 2^{\circ}$, de la Constitución Política de la República, toda vez que aquella disposición sólo permite el matrimonio entre un hombre y una mujer sin autorizar que las parejas homosexuales puedan contraer matrimonio;

\section{Reserva LEGAL}

(...)

Séptimo: Que, a mayor abundamiento, cabe precisar que los efectos y la regulación de las proyecciones del matrimonio son propios de la reserva legal y no constitucional. Ello quedó en evidencia en la discusión de la Comisión de Estudio de la Nueva Constitución, referida a la disolución del matrimonio, la que, por lo demás, con posterioridad a la entrada en vigencia de la Carta de 1980 fue aceptada y regulada bajo la forma del divorcio vincular. Es así como las características de la institución, referidas a la protección y desarrollo de la misma, han podido mutar en virtud de diversas normas de rango legal, las que han efectuado cambios en lo que atañe, por ejemplo, al régimen de bienes, a la adopción y a la filiación, entre otros aspectos;

\section{Falta DE IDONEIDAD DE LA INAPLICABILIDAD EN EL PRESENTE CASO}

Octavo: Que, sin perjuicio de lo razonado en cuanto al reproche constitucional de autos, esta Magistratura no puede pasar por alto que un examen detenido de la impugnación planteada no permite a su vez que se dicte sentencia estimatoria, toda vez que no se condice con el alcance de la acción de 
inaplicabilidad. En efecto, la acción de inaplicabilidad tiene como objetivo impedir que un determinado precepto legal sea aplicado en un caso concreto cuando de ello se pueden derivar consecuencias inconstitucionales. Así, la inaplicabilidad es un controlconcreto de constitucionalidad cuyo efecto es negativo, es decir, sólo impide que un precepto sea aplicado en la resolución de una gestión judicial pendiente. En consecuencia, en la gestión pendiente a que se refieren estos autos la única consecuencia que podría producirse de dictar sentencia estimatoria, sería la exclusión de la eventual aplicación del artículo 102 del Código Civil que define al matrimonio, la que se encuentra en el contexto de un amplio campo de normas que resultan aplicables por el juez de la gestión y que se refieren al estatuto jurídico del matrimonio;

Noveno: Que lo anterior implica que el requerimiento a que se refiere esta sentencia no pueda prosperar, toda vez que lo que se pretende por su intermedio es que se reformule un sistema de normas de modo integral y se regule positivamente una institución de modo distinto al actual. En efecto, si bien se ha efectuado una impugnación aislada de un artículo, lo que verdaderamente se impugna es la aplicación de un estatuto jurídico complejo derivado del vínculo matrimonial entre hombre y mujer, que se encuentra regulado en su estructura esencial en el Código Civil y en la Ley No 19.947, esto es, la Ley de Matrimonio Civil. En otras palabras, lo que pretenden los recurrentes es que se les reconozca la aplicación del mencionado estatuto, cuestión que no es de competencia de este Tribunal, pues éste no se encuentra facultado para modificar y regular las instituciones que contempla el ordenamiento jurídico mediante un pronunciamiento de inaplicabilidad. A mayor abundamiento, el requerimiento de autos tampoco puede considerarse bien formulado, toda vez que dos de las parejas que son parte en la acción de protección sub lite se casaron en el extranjero, sin que la Corte de Apelaciones de Santiago solicitara la inaplicabilidad de diversas normas de la Ley de Matrimonio Civil y, en especial, del artículo 80 de aquel cuerpo normativo que establece que "los requisitos de forma y fondo del matrimonio serán los que establezca la ley del lugar de su celebración. Así, el matrimonio celebrado en país extranjero, en conformidad con las leyes del mismo país, producirá en Chile los mismos efectos que si se hubiere celebrado en territorio chileno, siempre que se trate de la unión entre un hombre y una mujer". De esta manera, el reproche al artículo 102 del Código Civil no resulta decisivo en la resolución de la gestión pendiente en lo que se refiere a las aludidas parejas.

$Y$ teniendo presente lo dispuesto en los artículos $19, \mathrm{~N}^{\circ} 2,63, \mathrm{~N}^{\circ}$ s 3 y 20 , y 93 , inciso primero, $\mathrm{N}^{\circ} 6^{\circ}$, e inciso decimoprimero, de la Constitución Política de la República, así como en las normas pertinentes de la Ley $N^{\circ} 17.997$, Orgánica Constitucional de este Tribunal Constitucional,

Se resuelve: que se rechaza el requerimiento de inaplicabilidad deducido a fojas uno. 
Déjase sin efecto la suspensión del procedimiento decretada a fojas 54, debiendo oficiarse al efecto.

Voto particular concurrente del presidente del tribunal, ministro señor Raúl Bertelsen Repetto.

El Presidente del Tribunal, Ministro señor Raúl Bertelsen Repetto previene que concurre a la sentencia que rechaza el requerimiento de inaplicabilidad en que se impugna la aplicación del artículo 102 del Código Civil, sin compartir su considerando séptimo, pues la introducción legal del divorcio vincular es una materia ajena a la que se debate en autos por lo que no corresponde a esta Magistratura pronunciarse sobre la misma en esta oportunidad, y teniendo además presente las siguientes consideraciones:

(...)

3. Que, como es sabido, la igualdad ante la ley no exige un trato uniforme a todas las personas, sino que permite a la ley dar un trato diverso a las mismas cuando existe un hecho diferenciador relevante entre distintas personas, apto y proporcionado para la diferencia jurídica que se extraiga;

(...)

8. Que, teniendo en cuenta que es materia de ley la regulación del matrimonio, la definición del mismo contenida en el artículo 102 del Código Civil de 1855 y mantenida en la nueva Ley de Matrimonio Civil de 2004, al reservar su celebración sólo a personas de distinto sexo, no puede estimarse que constituye una diferencia arbitraria o caprichosa, sino fundamentada en las diferencias entre varón y mujer, que la ley, legítimamente, ha considerado y puede seguir considerando relevantes para establecer que los contrayentes sólo pueden ser un hombre y una mujer, razón por la que se conforma con la garantía constitucional de igualdad ante la ley y de ahí que la aplicación judicial del precepto legal impugnado no resulte contraria a la Constitución Política.

Voto Particular redactado por el Ministro que lo suscribe.

Voto particular concurrente de los ministros señores Marcelo Venegas Palacios, Enrique Navarro Beltrán e Iván Aróstica Maldonado.

Los Ministros señores Marcelo Venegas Palacios, Enrique Navarro Beltrán e Iván Aróstica Maldonado dejan constancia de que estuvieron por pronunciarse derechamente sobre el fondo del requerimiento deducido por la Corte de Apelaciones de Santiago, declarando que no resulta contraria a la Constitución la aplicación del artículo 102 del Código Civil, en el proceso sobre Recurso de Protección N6787-2010.

Fundamentan su decisión en lo razonado en los considerandos Primero a Cuarto de la sentencia de mayoría, con excepción del Ministro señor Enrique Navarro Beltrán, que también coincide con sus considerandos Quinto, Sexto y Séptimo, no suscribiendo, ninguno de dichos ministros, en lo demás, el voto de la mayoría, teniendo en su lugar y especialmente presente, los siguientes motivos: 
“La constitucionalidad del artículo 102 del Código Civil ante el tribunal COnStitucional. Comentario CRítICO DEL REQUERIMIENTO DE INAPLICABILIDAD FALLADO EN LA SENTENCIA Rol № 1.881, DE 3 DE NOVIEMBRE DE 2011"

(...)

7. Siendo el reproche constitucional que amenaza condenar la aplicación del artículo 102 del Código Civil en la gestión que se sigue en la Corte de Santiago, la arbitrariedad en que dicho precepto legal incurriría al reservar el contrato de matrimonio únicamente a personas de distinto sexo, excluyendo a las del mismo sexo, conviene tener presente que tal exigencia, respecto de la calidad de las partes que pueden celebrar dicho contrato, es una excepción a la regla general aplicable a toda clase de contratos, consagrada en su artículo 1438 del citado cuerpo legal, según el cual en todo contrato "cada parte puede ser una o muchas personas", sin distinción del sexo de ellas. Pero también dicha regla hace ostensible que el sexo de las partes no es la única excepción que el precepto cuestionado contiene respecto de las partes que pueden válidamente celebrar el contrato de matrimonio, pues también prohíbe que cada parte sea más de una persona: "un hombre y una mujer", puntualiza el artículo 102, cuestión ésta que no debe resultar indiferente al resolver sobre la inconstitucionalidad de su aplicación en la decisión de gestiones judiciales;

8. Al entrar estos jueces a resolver la cuestión debatida tienen presente la frondosa jurisprudencia sobre el principio de igualdad constitucional que esta Magistratura ha desarrollado, que se inicia con la sentencia recaída en el proceso Rol 28, de 1985 y alcanza su mayor extensión, más recientemente, en las sentencias dictadas en los procesos roles 1254-09, 1287-09, 1399-09 y 1710-10. En sus rasgos esenciales la doctrina allí sentada señala que la igualdad ante la ley no exige un trato uniforme a todas las personas, sino que permite al legislador dar un trato diverso a las mismas cuando existe un hecho diferenciador relevante entre las distintas personas o grupos de personas, apto y proporcionado para la diferencia jurídica que se extraiga;

9. En esta perspectiva, la disposición objetada, al reservar la celebración del matrimonio sólo a personas de distinto sexo, no puede estimarse que consagre una diferencia arbitraria o caprichosa, pues es ostensible que su fundamento está en las diferencias naturales entre varón y mujer, que la ley legítimamente ha estimado relevantes para establecer diferencias, como ocurre, por ejemplo, en la legislación laboral y previsional. Del mismo modo resulta claramente razonable, y no arbitrario o caprichoso, que quienes celebran el contrato matrimonial definido en el artículo 102 del Código Civil, sean, precisamente, un hombre y una mujer, habida consideración a las finalidades de dicho contrato, establecidas en la misma norma cuestionada;

(...)

12. Con lo razonado en los motivos precedentes podemos afirmar que el contrato de matrimonio definido en el artículo 102 del Código Civil, disciplinado además por otras numerosas disposiciones del mismo cuerpo legal y por la Ley de Matrimonio Civil, entre otras leyes que lo regulan desde diversas perspectivas 
es, por su concepción misma, por su origen histórico social, por su fisonomía y por sus finalidades propias, una institución aplicable únicamente a las relaciones de parejas formadas por un hombre y una mujer, no siendo admisible concluir, de dicha característica propia de la institución matrimonial tal y como está actualmente consagrada en la legislación civil chilena, que la aplicación del artículo 102 del Código Civil pueda resultar contraria a la Constitución cuando fundamenta la negativa de un Oficial Civil de celebrar el matrimonio de dos varones entre sí. Por el contrario, estimamos que su aplicación en tal caso no resulta contraria a la Constitución, y así debe declararlo este Tribunal Constitucional;

(...)

14. Si bien nuestro voto descarta la inconstitucionalidad del artículo 102 del Código Civil, no afirma ni niega que la Constitución acepte, promueva, impida o condene la posibilidad de que parejas homosexuales puedan convivir y realizar una vida afectiva en común protegida por el ordenamiento jurídico, pues corresponde al Legislador, y no a esta Magistratura Constitucional, dar forma a las nuevas instituciones legales que vengan a dar satisfacción a las necesidades de la marcha de la sociedad, teniendo en cuenta las mutaciones que ella experimenta en su constante evolución.

Sobre la constitucionalidad o inconstitucionalidad de las opciones legislativas que los Poderes Colegisladores eventualmente escojan en dicho propósito, se cuidarán estos jueces de adelantar opinión, pues la prudencia que debe gobernar el ejercicio de nuestro ministerio nos exige guardar silencio sobre conflictos futuros, aún más si son hipotéticos, ya que así procuramos ofrecer a la sociedad, más cumplidamente, la garantía de objetividad e imparcialidad que los jueces le debemos.

Voto Particular redactado por el Ministro señor Marcelo Venegas Palacios.

Voto particular concurrente de la ministra señora Marisol Peña Torres.

Se previene que la Ministra señora Marisol Peña Torres concurre a la sentencia, teniendo presente, además, las siguientes consideraciones:

(...)

$3^{\circ}$. Que el matrimonio entre un hombre y una mujer constituye base esencial de la familia amparada por la Constitución, porque muchas de las funciones atribuidas a ésta se relacionan con los fines que el legislador del Código Civil asigna al matrimonio, pero particularmente, con la de procrear. Así, la familia constituida por la unión matrimonial estable entre un hombre y una mujer no sólo contribuye al logro de las demás funciones del matrimonio -vivir juntos y auxiliarse mutuamente-, sino que resulta decisiva para la supervivencia y proyección de la sociedad a través del tiempo, perspectiva que, sin duda, debe ser tenida en cuenta por el legislador al regular los efectos del matrimonio. Dicho, en otros términos, esta regulación no puede prescindir del hecho que el matri- 
monio entre un hombre y una mujer resulta fundamental para que la familia se consolide como verdadero núcleo fundamental de una sociedad que aspira a seguir existiendo a través de la renovación progresiva de las generaciones que se produce a partir de dicha unión.

Así, la importancia social del matrimonio, expresada en los fines que le asigna el artículo 102 del Código Civil, lo configura como una verdadera institución, a la cual está asignada, entre otras funciones, la de procrear, esto es, el proceso completo por el que se trae un nuevo individuo al mundo (Dorland, William. Diccionario Enciclopédico Ilustrado de Medicina. Editorial Elsevier, $30^{a}$. Edición, Madrid, 2005), lo que sólo puede ser logrado a través de la unión de dos células, masculina y femenina, como las que se encuentran en el acto carnal entre un hombre y una mujer;

(...)

Voto particular concurrente de los ministros señores Francisco Fernández Fredes, Carlos Carmona Santander, José Antonio Viera-Gallo Quesney y Gonzalo García Pino.

Se previene que los Ministros señores Francisco Fernández Fredes, Carlos Carmona Santander, José Antonio Viera-Gallo Quesney y Gonzalo García Pino concurren a la sentencia, teniendo presentes, además, las siguientes consideraciones:

(...)

10. Que, al estar regulado en la ley, el matrimonio adquiere el rango y la fuerza de este tipo de normas. Ello implica, por de pronto, que una ley puede modificarlo. Las leyes, de acuerdo al artículo 63 de nuestra Constitución, se aprueban, modifican o derogan por otras leyes.

Enseguida, esto implica que no podemos constitucionalizar lo establecido en preceptos legales. El Tribunal Constitucional interpreta la Constitución, pero no la crea. No puede darle rango constitucional a normas dictadas por el Poder Legislativo, no por el poder constituyente. La Constitución establece su propio mecanismo de incorporación de normas a su texto. Dicho mecanismo debe ser acatado por todos los órganos del Estado, incluido el Tribunal Constitucional, quien también debe "someter su acción a la Constitución" (STC Rol 1284/2009).

Asimismo, como se ha sostenido en esta sentencia, no podemos desnaturalizar el recurso de inaplicabilidad. El Tribunal no resuelve una inaplicabilidad en base a una norma legal; el precepto legal es el objeto de su examen, pero no su referente. Las leyes que examina no pueden ser, a la vez, norma examinada y norma examinante. En este recurso se enjuicia una norma legal en su confrontación con la Constitución, no con una ley (STC Rol 1284/2009).

Tampoco podemos darle un valor absoluto a una norma legal, en circunstancias que puede haber otras que apunten en un sentido distinto o contradictorio. 
No existe una opción del constituyente por erigir un modelo determinado de unión heterosexual. Si el constituyente se mantiene neutral frente a las preferencias del legislador al momento de definir el matrimonio, esta Magistratura no puede cerrar esa opción. Si el matrimonio hoy es entre un hombre y una mujer, no es porque lo diga o lo establezca la Constitución, sino la ley.

Finalmente, no podemos igualar un concepto constitucional con uno legal. Ello puede rigidizar lo que el constituyente dejó abierto a la configuración legislativa, impidiendo su adaptación en el tiempo;

(...)

22. Que, en consecuencia, el Estado debe proteger no sólo a la familia fundada en el matrimonio, sino que tal deber también abarca a las familias de facto, sea que se constituyan por una pareja heterosexual o no.

Por ello, existiendo diversos modelos de familia protegidos por la Constitución y considerando que el matrimonio no es la única forma de conformar una familia, no hay, entonces, razones para sostener que se afecta el deber del Estado de proteger a la familia si la ley restringe el matrimonio sólo a personas de sexos diferentes;

La igualdad y el artículo 102 del Código Civil.

(...)

24. Que la igualdad es un principio informador de todo el ordenamiento jurídico, en donde se "configuran principios y valores básicos de fuerza obligatoria que impregnan toda la Constitución de una finalidad humanista" (STC 1185, C.11). Por tanto, la igualdad constituye una presión permanente sobre el sistema legal y social; es un desafío constante por consagrar una mayor justicia material en un contexto social y cultural donde todavía subsisten desigualdades significativas.

A su vez, se trata de un derecho fundamental que "reconoce la titularidad de toda persona sobre el bien jurídico igualdad, que es oponible a todo destinatario y queimplica el derecho a no ser discriminado por razones de carácter subjetivo u otras que resulten relevantes, con el consiguiente mandato correlativo respecto de los órganos o autoridades estatales y los particulares de prohibición de discriminación." (Nogueira, Humberto: Derechos fundamentales y garantías constitucionales, Tomo 2, Librotecnia, Segunda Edición, 2008, p. 223);

25. Que el derecho a no ser discriminado arbitrariamente engendra una cuestión básicamente relacional: el test de igualdad debe realizarse en consideración con otras personas, casos, situaciones u otros derechos fundamentales. $\mathrm{Al}$ respecto se ha señalado que: "La igualdad designa un concepto relacional, no una cualidad de una persona, de un objeto (material o ideal) o de una situación, cuya existencia pueda ser afirmada o negada como descripción de esa realidad aisladamente considerada; es siempre una relación que se da al menos entre dos personas, objetos o situaciones." (Rubio Llorente, Francisco: 
"La constitucionalidad del artículo 102 del Código Civil ante el tribunal COnStitucional. Comentario CRítICO DEL REQUERIMIENTO DE INAPLICABILIDAD FALLADO EN LA SENTENCIA ROL No 1.881, DE 3 DE NOVIEMBRE DE 2011"

La forma del poder, Centro de Estudios Constitucionales, 1993, p. 640). "En efecto, la igualdad sólo es posible entenderla y conceptualizarla a partir de la existencia de otros sujetos titulares del mismo derecho, de modo que se deba determinar con ello quiénes entran en la categoría de la igualdad y quiénes en la de la desigualdad". (Ministerio Secretaría General de la Presidencia: Doctrina Constitucional del Presidente Ricardo Lagos Escobar (2000-2006), Tomo I, LOM, 2010, p. 389);

26. Que de acuerdo a lo sostenido reiteradamente por esta Magistratura, el parámetro de control de la igualdad es el juicio de razonabilidad. "La razonabilidad es el cartabón o estándar que permite apreciar si se ha infringido o no el derecho a la igualdad ante la ley asegurado por el artículo $19 \mathrm{~N}^{\circ} 2^{\circ}$ de la Constitución. De esta manera, la garantía de la igualdad ante la ley no se opone a que la legislación contemple tratamientos distintos para situaciones diferentes, siempre que tales distinciones o diferencias no importen favores indebidos para personas o grupos (STC 1365, C. 29; STC 28; STC 53; STC 219; STC 1138, C. 24; STC 1140, C. 19)";

27. Que lo anterior es relevante, porque debe tenerse en consideración que las categorías "sexo" y "orientación sexual" corresponden a las denominadas categorías sospechosas de discriminación que inciden en el juicio de razonabilidad. Cuando se recurre a ellas, se invierte la presunción de constitucionalidad de que goza el legislador en virtud del principio de deferencia, ya que pueden afectar a personas integrantes de colectivos minoritarios más vulnerables en razón de una trayectoria de discriminación. Lo anterior exige realizar un examen más estricto de razonabilidad. Así se desprende de los artículos $1^{\circ}$ y $19 \mathrm{~N}^{\circ} 2^{\circ}$ de la Constitución, que señalan respectivamente que todas las personas nacen libres e iguales en dignidad y derechos y que hombres y mujeres son iguales ante la ley. Por su parte, el mismo criterio es empleado por el Código Civil, al definir qué debe entenderse por persona (artículo 55), así como el Código del Trabajo (artículo $2^{\circ}$ ) y el Estatuto Administrativo (artículo 17), respecto del acceso igualitario al trabajo y a la función pública, respectivamente.

Además, en el Pacto Internacional de Derechos Civiles y Políticos, en su artículo 2.1, se sostiene que el Estado debe respetar y garantizar a los individuos que se encuentren en su territorio y estén sujetos a su jurisdicción los derechos reconocidos en dicho Pacto, y señala enseguida: "sin distinción alguna de raza, color, sexo, idioma, religión, opinión política o de otra índole, origen nacional o social, posición económica, nacimiento o cualquier otra condición social", identificando así una serie de criterios sospechosos de discriminación, entre los que se encuentra el sexo y se comprende la orientación sexual. Lo mismo hace la Convención Americana, en su artículo 1.1, al señalar que el Estado se compromete a respetar los derechos y libertades reconocidos en dicho tratado sin discriminación, principio que se ve reforzado en el artículo 24 de dicha 
Convención, que consagra la igualdad ante la ley. Ello se ve reforzado por lo dispuesto en la Convención Interamericana para Prevenir, Sancionar y Erradicar la Violencia contra la Mujer, Convención de Belén Do Pará, y en la Convención sobre la Eliminación de Todas las Formas de Discriminación contra la Mujer.

Como lo ha sostenido este Tribunal, el empleo de estos criterios sospechosos puede transformarse en una categoría contraria a la igualdad ante la ley cuando manifieste el "propósito de hostilidad contra determinada persona o grupo de personas" (STC Rol 986/2008; STC Rol 1414/2010);

28. Que, como se ha indicado, el legislador ha reconocido los efectos jurídicos de las relaciones entre parejas del mismo sexo, principalmente para efectos punitivos. Sin embargo, nuestro ordenamiento jurídico no contempla ninguna regulación explícita y completa de ese tipo de uniones. Cuando se excluye la proyección pública de una relación homosexual a través de los mecanismos que el legislador determine, se está sosteniendo, directa o indirectamente, que se trata de un tipo de relaciones de una calidad insuficiente, incapaz de dar origen a un conjunto claro de derechos y deberes. La omisión del legislador genera una situación de vulnerabilidad y grave desprotección para las uniones de personas del mismo sexo.

Desde un tiempo a esta parte se han presentado diversas iniciativas de ley destinadas a llenar ese vacío y a poner término a una falta de cumplimiento del deber del Estado de brindar protección y reconocimiento a ese tipo de convivencias;

(...)

Corolarios

34. Que, al determinar el artículo 102 del Código Civil que el matrimonio es un contrato solemne que sólo puede celebrarse entre un hombre y una mujer, establece una definición legal. Nada obsta a que, desde el punto de vista constitucional, el legislador cambie esta regla;

35. Que para efectuar tal modificación o para regular la convivencia de personas del mismo sexo, el legislador debe considerar que todas las personas, más allá de su orientación sexual, gozan de dignidad y de la libertad necesaria para desenvolver su personalidad, así como de la protección que el Estado debe brindar a su vida privada personal y familiar.

La sexualidad forma parte de la privacidad y es una manifestación del derecho al libre desarrollo de la personalidad, como lo ha reconocido el Tribunal Constitucional de Alemania al afirmar que toda persona tiene derecho a determinar su definición sexual y su relación con la sexualidad, respetando la dignidad y libertad de los demás.

Las personas son libres de vivir en pareja y constituir lazos familiares. El Estado debe reconocer esa realidad, respetarla y brindarle amparo, guardando consideración de los derechos de las personas y los principios constitucionales 
$y$, por consiguiente, sin establecer ninguna diferencia que pudiera ser arbitraria;

36. Que legislar sobre la materia resulta aún más imperioso en nuestro país frente al vacío normativo que hoy existe. Ello deja en una incertidumbre jurídica a las uniones de hecho, especialmente a las parejas del mismo sexo, exponiéndolas a situaciones de menoscabo y desamparo. Existe en este punto una omisión legislativa y un déficit de protección que es preciso remediar con prontitud. Existe una clara tendencia a regular estas situaciones en los diversos países;

37. Que, sin embargo, debemos dejar en claro que compete al Parlamento -y no a esta Magistratura- dictar las normas legales correspondientes, regulando alguna forma de unión civil entre dos personas, independientemente de su orientación sexual, e incluso abriendo la institución matrimonial a personas del mismo sexo, si así lo estima conveniente.

Voto Particular redactado por los Ministros que lo suscriben.

Voto disidente del ministro señor Hernán Vodanovic Schnake.

Acordada la sentencia con el voto en contra del Ministro señor Hernán VodanovicSchnake, quien estuvo por acoger la acción de inaplicabilidad interpuesta, por las siguientes razones:

(...)

\section{SOBRE EL FONDO}

Comparto y suscribo los fundamentos de la prevención de los Ministros Fernández, Carmona, Viera-Gallo y García, con excepción de lo expuesto en los numerales 2, 3 y 22 (acápite final). Sin embargo, por dichas motivaciones y las que se manifiestan a continuación, estimo que el requerimiento debe ser acogido y declararse inaplicable el artículo 102 del Código Civil en la gestión sublite.

1). En 1857 (Scott v. Sandford), el Tribunal Supremo norteamericano, con una interpretación originalista, declaró la esclavitud conforme a la doctrina de sus textos fundamentales. Sólo transcurrieron algunas décadas para considerar lamentable esa decisión, que contradijo la conciencia cívica de su época.

Una disposición legal puede acomodarse perfectamente al sistema jurídico constitucional del momento en que es dictada, como ocurre con el artículo 102 del Código Civil, perteneciente al texto que data de 1855 . Pero siglo y medio después puede contradecir los valores, principios y derechos fundamentales que la Constitución consagra, tal cual son entendidos en este otro momento.

Por eso, la Corte Constitucional de Sudáfrica (en sentencia de uno de diciembre de dos mil cinco) cuando invalidó la cláusula heterosexual del régimen matrimonial, pudo afirmar que "conforme cambian las condiciones de la humanidad y las ideas de la justicia y la igualdad evolucionan, los conceptos de los 
derechos también adquieren una nueva textura y significado. El horizonte de los derechos es ilimitado como lo son los deseos y las expectativas de la humanidad. Lo que ayer era considerado como justo por el derecho, hoy es condenado como injusto". Cuando se adoptó la Declaración Universal de los Derechos Humanos, el colonialismo y la discriminación eran vistos como fenómenos naturales, consagrados en las leyes de las naciones consideradas civilizadas y bendecidos por muchos líderes religiosos al momento de su denuncia. El patriarcado, al menos tan viejo como la mayoría de los sistemas matrimoniales, defendido por tener sustento en un hecho biológico y condonado por muchos líderes religiosos, ya no es aceptado como la norma, al menos en una gran parte del mundo. La castración severa de las mujeres y los niños era tolerada por el derecho familiar y los instrumentos del derecho internacional en ese entonces, pero hoy se considera intolerable. De manera similar, aunque muchos de los valores familiares han permanecido constantes, tanto la familia como el derecho familiar se han transformado profundamente" (párrafo 102).

No se trata, entonces, de indagar sólo la intención del Constituyente, sino de reconocer cuál es la orientación y sensibilidad que prevalece hoy día, cómo se resuelven las diferencias o conflictos de valores y principios en este momento y cuáles son los que ostentan preeminencia.

(...)

2). Si se analiza la argumentación fundante de la exclusión del matrimonio entre iguales, se advertirá que el único principio constitucional (o bien jurídico protegido) invocado es la intangibilidad de la familia.

De contrario, los principios y derechos que se esgrimen para su defensa son la libertad, igualdad y dignidad de las personas, así como el conjunto de derechos de la personalidad.

Por un lado, se consideran como básicas prescripciones constitucionales que merecerían resguardo privilegiado, tales como "la familia es el núcleo fundamental de la sociedad", "el Estado reconoce y ampara los grupos intermedios y les garantiza la adecuada autonomía para cumplir sus propios fines" y "es deber del Estado dar protección a la familia" y propender a su fortalecimiento.

Por el otro, se califican como vitales los mandatos relativos a que "las personas nacen libres e iguales en dignidad y derechos", que "el Estado está al servicio de la persona humana y su finalidad es promover el bien común, para lo cual debe contribuir a crear las condiciones sociales que permitan a todos y a cada uno de los integrantes de la comunidad nacional su mayor realización espiritual y material posible" y que "es deber del Estado promover la integración armónica de todos los sectores de la Nación y asegurar el derecho de las personas a participar con igualdad de oportunidades en la vida nacional".

No hay duda que, para sus protagonistas, el matrimonio entre personas del mismo sexo expresa la plena realización de los valores de libertad, igualdad 
y dignidad humanas. Si se entendiera que hay oposición entre el ejercicio de tales derechos y la protección de la familia, una ponderación razonable del conflicto no puede sino dar preeminencia a la dignidad y derechos humanos de las personas por sobre los intereses de una institución social, por trascendente y respetable que ella sea.

3). Dígase lo que se diga, la resolución del asunto pasa por la consideración de la homosexualidad. Es ésta, como toda orientación sexual, digna de ser reconocida y protegida o, por el contrario, una condición negativa, objeto de censura y reproche. En el largo recorrido histórico de la discriminación, a lo menos se ha pasado ya de su calificación como delito (sodomía) a su estimación como simple cualidad indeseable, un virus social que no debe propagarse. En sociedades culturalmente atrasadas, no adviene aún el momento de la tolerancia con la pura diferencia. Por eso, la regla jurídica es tan importante para afirmar positivamente esta distinción, como se ha hecho ya con la llamada raza, el género y la discapacidad.

\section{(...)}

5). El punto esencial no reside en las características estructurales del matrimonio, como se verá, sino en determinar si la exclusión de las parejas del mismo sexo en el acceso a dicha institución constituye o no una discriminación arbitraria.

No obstante, ya que el único fundamento de la tesis contraria descansa en la supuesta naturaleza existencial de la heterosexualidad como fundamento del matrimonio, habrá que referirse al mismo.

En primer término, no debe desatenderse que la institución matrimonial, como cualquier otra, es una construcción social histórica. Sus elementos esenciales no son, necesariamente, los de ayer ni serán forzosamente los de mañana. Ha sido tradicionalmente una forma de institucionalizar la vida en común de una pareja heterosexual, pero nada impide - desde una visión secular- que acoja a parejas homosexuales o del mismo sexo (ambas cuestiones no son lo mismo; así, dentro de la actual legislación chilena no hay impedimento para que celebren el acto matrimonial uno o ambos contrayentes homosexuales).

En el matrimonio actual se ha perdido la función relevante de procrear (la mayoría de los hijos nacen fuera del matrimonio y la aptitud para generar descendencia no es un requisito para celebrarlo), en desmedro de las finalidades propias de la vida en común. El objetivo esencial, más bien, expresa fines de solidaridad, afecto y asistencia recíproca.

Siendo así las cosas, debe invertirse la carga de la argumentación. Son los postulantes de la exclusividad heterosexual en el matrimonio quienes deben exponer las razones que la sostienen. Desde luego, procede descartar el razonamiento circular de que ello es así porque debe serlo y siempre lo ha sido. Tal aseveración simplemente nada explica. En definitiva, se aprecia la inexistencia 
de una justificación racional, de un fin lícito en la interdicción del matrimonio entre iguales.

El matrimonio "ideal" exige, de toda forma, probar que la exclusión de parejas del mismo sexo protege la unión heterosexual; sin embargo, no hay perjuicio alguno en la ocurrencia de ello. La prohibición no es necesaria para proteger los derechos de aquellos que sí pueden casarse. Aún mas, los detractores no han meditado que -en vez de verse debilitado por la inclusión de otros actores- la incorporación de parejas hoy excluidas a la institución matrimonial, la amplía y probablemente la fortalece.

La búsqueda de supuestos de hecho diversos no debe realizarse mediante una comparación entre las diferencias fácticas de ambos, sino a través del fundamento de la norma, es decir, mediante la comprobación de si los distintos supuestos tienen diferente significación jurídica o no respecto a dicho fundamento.

La indagación establece que se trata de supuestos de hecho similares, pues en ambos casos se trata de la unión de dos personas plenamente capaces, que pretenden formar una comunidad de vida para construir un proyecto común. Así, el fundamento último de la norma, que es formalizar y legitimar el vínculo de dos personas para ejercer libremente su derecho a formar una comunidad de vida, es plenamente cumplido.

Por último, la regulación legal de las parejas del mismo sexo -ciertamente una mejoría en el maltrato social que les concierne- no borra la discriminación denunciada. Como se ha reiterado, ésta se produce por la exclusión del matrimonio.

6). Los criterios limitados que se han expresado en sentencias del Consejo de Estado francés, Tribunal Europeo de Derechos Humanos o Tribunal Supremo de Alemania, que no han trascendido las posibilidades del reconocimiento jurídico de las uniones de hecho, se citan fuera del contexto cultural que los cobija, en sociedades donde la orientación sexual es un atributo, condición y bien reconocidos por la comunidad. Lo cierto es que el acceso de las parejas del mismo sexo a la institución matrimonial es una tendencia creciente en sociedades de alto desarrollo cultural, habiéndose consagrado ya en Bélgica, Holanda, Canadá, España y Argentina y en diversos estados de Norteamérica, así como en el Distrito Federal de México. Anteriormente el Tribunal Supremo de EE.UU. sentó las bases para legitimar el matrimonio entre parejas del mismo sexo cuando, en 1967 (en el caso Loving v. Virginia), anuló la prohibición de matrimonios interraciales, estimando el matrimonio como un derecho fundamental, y en 2003 (en el caso de Lawrence v. Texas), declaró la inconstitucionalidad de la calificación delictual de las relaciones homosexuales consentidas.

III. Conclusiones.

7). Esta disidencia hará suya las conclusiones del informe presentado por Libertades Públicas AG, consignadas a fojas 189 y 190, y que se transcriben: 
“La constitucionalidad del artículo 102 del Código Civil ante el tribunal COnStitucional. Comentario CRÍTICO DEL REQUERIMIENTO DE INAPLICABILIDAD FALLADO EN LA SENTENCIA ROL N N 1.881, DE 3 DE NOVIEMBRE DE 2011"

(...)

5. Privar a un grupo de personas de la posibilidad de acceder a la institución matrimonial importa negarles la dignidad que la propia Constitución les reconoce, impidiéndoles el acceso a una institución considerada socialmente indispensable para el pleno desarrollo de una vida buena; e implica desconocer toda dimensión pública a la relación construida por los miembros de la pareja, desde el momento que se les niega la posibilidad de comprometerse públicamente ante sus semejantes, tratamiento discriminatorio en perjuicio de las parejas del mismo sexo que no cuenta con ninguna justificación razonable en una República democrática que acepta la diversidad de formas de vida.

6. Finalmente, la señalada discriminación no sólo tiene efectos en el ámbito simbólico. En nuestro ordenamiento, el matrimonio desarrolla sus consecuencias mucho más allá del ámbito de las relaciones familiares, siendo considerado en innumerables disposiciones como condición o preferencia para el goce de ciertos derechos. Pues bien, desde el momento que se priva a las parejas del mismo sexo de la posibilidad de acceder a esta institución social, el Estado también les está vedando el acceso a una serie innumerable de ventajas asociadas al estatus de casado, confiriéndoles de esta forma un tratamiento discriminatorio, que dificulta o incluso impide la realización de un plan de vida que consideran indispensable para su propia felicidad.

7. Todo lo señalado precedentemente nos permite arribar a una única conclusión: El Estado, cuando niega a las parejas del mismo sexo la posibilidad de participar en una de nuestras más gratificantes y preciadas instituciones comunitarias, está incurriendo en una exclusión que es incompatible con el respeto de la dignidad humana, la autonomía individual y la igualdad ante la ley, al tiempo que incumple con el mandato constitucional de protección a la familia, entendido en términos amplios. La demanda de las parejas del mismo sexo no persigue que se les confiera un tratamiento especial, sino simplemente poder participar de los beneficios de la vida en sociedad, accediendo en términos de igualdad a una institución considerada indispensable para el desarrollo de los propios planes de vida, como es el matrimonio. Por estas razones, el artículo 102 del Código Civil debe ser declarado inconstitucional."

Voto Disidente redactado por el Ministro que lo suscribe.

Redactaron la sentencia los Ministros que la suscriben, y los votos particulares concurrentes y el voto disidente, los Ministros que se indican en cada uno de ellos.

Comuníquese, notifíquese, regístrese y archívese.

Rol No 1.881-10-INA.

Pronunciada por el Excmo. Tribunal Constitucional, integrado por su Presidente, Ministro señor Raúl Bertelsen Repetto, y por los Ministros señores Marcelo Venegas Palacios, Hernán Vodanovic Schnake, señora Marisol Peña 
Torres y señores Enrique Navarro Beltrán, Francisco Fernández Fredes, Carlos Carmona Santander, José Antonio Viera-Gallo Quesney, Iván Aróstica Maldonado y Gonzalo García Pino.

Se certifica que el Ministro señor Francisco Fernández Fredes concurrió al acuerdo y fallo, pero no firma por encontrarse haciendo uso de su feriado legal.

Autoriza la Secretaria del Tribunal, señora Marta de la Fuente Olguín.

La constitucionalidad del artículo 102 del Código Civil ante el Tribunal Constitucional. Comentario crítico del requerimiento de inaplicabilidad fallado en la sentencia rol 1881, de 3 de noviembre de 2011.

\section{INTRODUCCIÓN}

La sentencia Rol № 1.881-10-INA, en la que el Tribunal Constitucional rechazó el requerimiento de inaplicabilidad contra el artículo 102 del Código Civil, ofrece abundante material de análisis. Pero entre las materias que pueden ser analizadas, las hay que son comunes con otros fallos del Tribunal Constitucional y las hay que son específicas de este caso. Me interesan las segundas.

Entre las materias de la sentencia Rol № 1.881 que son interesantes de analizar, pero que no son específicas de este fallo, se cuentan, por ejemplo, el rechazo del requerimiento por un motivo para haberlo declarado inadmisible; ${ }^{1}$ el valor que tienen los votos particulares de la sentencia; ${ }^{2}$ la naturaleza del control que efectúa el Tribunal Constitucional a través de la inaplicabilidad, ¿es concreto o abstracto ${ }_{;}^{3}$ la existencia de las esferas de la legalidad y de la constitucionalidad, como factores determinantes de la competencia del Tribunal Constitucional. ${ }^{4}$

En cambio, lo que es específico de esta sentencia y digno de análisis es el enjuiciamiento del artículo 102 del Código Civil según el principio constitucional de igualdad. Es lo que el propio Tribunal definió como la cuestión sobre la que debía pronunciarse: "si la aplicación del artículo 102 del Código Civil (...) infringe o no la garantía de igualdad ante la ley" (cons. 4º). Esta es la materia que me interesa abordar a continuación.

\footnotetext{
${ }^{1}$ Cfr. la última oración del cons. $9^{\circ}$.

2 El modo como esta decisión se ha informado por los medios de comunicación y alguna polémica entre profesores, hace interesante el punto.

${ }^{3}$ Porque en este caso, es evidentemente abstracto. Aunque el Tribunal Constitucional haya definido que la cuestión a decidir era si la aplicación del artículo 102 del Código Civil era contraria a la Constitución (cons. $4^{\circ}$ ), lo cierto es que lo cuestionado fue la definición de matrimonio, con independencia del contexto de su aplicación. Pese a lo dicho, es innegable que hubo una circunstancia de hecho que determinó el examen de la norma legal: la homosexualidad de las personas que recurrieron de protección.
}

${ }^{4}$ Es lo que entendemos que subyace en el cons. $7^{\circ}$. 
“La constitucionalidad del artículo 102 del Código Civil ante el tribunal COnStitucional. Comentario CRítICO DEL REQUERIMIENTO DE INAPLICABILIDAD FALLADO EN LA SENTENCIA Rol № 1.881, DE 3 DE NOVIEMBRE DE 2011"

\section{Lo que la sentencia dijo sobre el punto: nada. Pero...}

La sentencia Rol № 1.881 no se pronunció sobre la constitucionalidad del ar-tículo 102 del Código Civil a la luz del principio de igualdad; soslayó la cuestión de fondo anteponiendo una objeción de forma. El requerimiento no se acogió, porque el precepto impugnado no resultaba decisivo para la resolución del asunto. El artículo 102 del Código Civil formaba un entramado del cual era inútil separarlo declarándolo inaplicable para el caso concreto. Y es que el Tribunal Constitucional entendió que "lo que verdaderamente se impugna es la aplicación de un estatuto jurídico complejo derivado del vínculo matrimonial entre hombre y mujer" (cons. $9^{\circ}$ ).

Aunque la sentencia nada dijo sobre la constitucionalidad del artículo 102 del Código Civil, nuevo de los diez ministros del Tribunal sostuvieron en sus votos que era constitucional. Su Presidente, Ministro Bertelsen, dijo: "la definición [de matrimonio] contenida en el artículo 102 del Código Civil (...) se conforma con la garantía constitucional de igualdad ante la ley y de ahí que la aplicación judicial del precepto legal impugnado no resulte contraria a la Constitución Política" (punto 8 del voto); la Ministra Peña no lo afirma expresamente, pero su argumento no deja lugar a dudas; el voto de los ministros Venegas, Navarro y Aróstica dice: "...nuestro voto descarta la inconstitucionalidad del artículo 102 del Código Civil" (punto 14 del voto), y los ministros Fernández, Viera-Gallo, Carmona y García no lo afirmaron explícitamente, pero se infiere con facilidad de algunos pasajes de su voto: "no hay (...) razones para sostener que se afecta el deber del Estado de proteger a la familia si la ley restringe el matrimonio sólo a personas de sexos diferentes" (punto 22 del voto); “...el artículo 102 del Código Civil (...) establece una definición legal. Nada obsta a que, desde el punto de vista constitucional, el legislador cambie esta regla" (punto 34 del voto).

Pero los votos particulares y la sentencia son cosas diferentes. Puesto que la sentencia no decidió si el artículo 102 del Código Civil era contrario al principio de igualdad o no, lo que se comentará a continuación es lo que se dijo en los votos particulares. Luego, no entiendo este trabajo como un estudio de lo que el Tribunal Constitucional dijo sobre el matrimonio (porque en realidad el Tribunal Constitucional no dijo nada; los votos particulares expresan la opinión de quien los suscribe); lo entiendo, en cambio, como un análisis del matrimonio heterosexual a la luz del principio constitucional de igualdad, aprovechando lo expresado en los distintos votos particulares de la sentencia.

\section{IGUALDAD, HOMOSEXUALIDAD Y MATRIMONIO}

La cuestión es, como ya se dijo, si la aplicación del artículo 102 del Código Civil es contrario al artículo $19 \mathrm{~N}^{\circ} 2$ de la Constitución. El artículo 102 del Código Civil define el matrimonio como "un contrato solemne por el cual un 
hombre y una mujer se unen actual e indisolublemente, y por toda la vida, con el fin de vivir juntos, de procrear y de auxiliarse mutuamente". Para juzgar si la definición legal de matrimonio es contraria al principio de igualdad, es preciso determinar un término de comparación, porque la igualdad es una cualidad relativa. Es decir, el juicio de igualdad depende de las cosas que se comparen y en qué se comparen.

Tres de los cinco votos particulares hicieron referencia a las características específicas de la aplicación del principio constitucional de igualdad, con más o menos referencias a la propia jurisprudencia del Tribunal. ${ }^{5}$ Basta con señalar que lo inconstitucional no es la discriminación per se, sino su falta de fundamento racional. Lo determinante en el test de igualdad que realiza el Tribunal Constitucional es que la diferencia no sea arbitraria, es decir, que entre los términos de la comparación exista(n) una(s) circunstancia(s) que justifique racionalmente la desigualdad, desde la perspectiva que se comparan.

En este caso, los términos de la comparación ¿cuáles son? Según el recurso de protección en que se originó el requerimiento de inaplicabilidad, los términos de la comparación son las personas, todas iguales en dignidad y derechos. El factor de la comparación (es decir, el aspecto bajo el cual se comparan) es el matrimonio (la posibilidad de contraerlo o de inscribir uno válidamente celebrado en el extranjero). Si todas las personas son iguales en dignidad y derechos, ¿por qué algunas pueden contraer/inscribir matrimonio y otras no? En la demanda de protección el texto es el siguiente: "...siendo intrínsecamente todas las personas iguales en dignidad y en derechos conforme consagra nuestra carta fundamental, el negar la posibilidad de contraer matrimonio, o de inscribir uno válidamente celebrado en el extranjero, a dos personas por su condición sexual constituye un grave atentado contra el derecho a la igualdad y un acto -a todas luces- arbitrario" ${ }^{6}$

El planteamiento de la controversia sobre el matrimonio heterosexual desde la perspectiva de la igualdad, no puede hacerse en términos tan simples como los que fundaron la demanda de protección. La igual dignidad y derechos de todas las personas no prueban que la definición del matrimonio del artículo 102 del Código Civil sea inconstitucional. La razón para demandar el recono-

\footnotetext{
${ }^{5}$ Bertelsen en el punto 3; Venegas, Navarro y Aróstica en el punto 8 y Fernández, Viera-Gallo, Carmona y García en los puntos 24 a 27, de sus respectivos votos.

${ }^{6}$ En la p. 3 del expediente, disponible en http://www.tribunalconstitucional.cl/wp/descargar_expediente.php?id=22087 [visitado el 20/11/2011]. Más adelante, en el mismo escrito, se dice: “...siendo intrínsecamente todas las personas iguales en dignidad y en derecho conforme consagra nuestra carta fundamental, el negar la posibilidad de contraer matrimonio a dos personas por su condición sexual constituye un grave atentado contra el derecho que busca proteger esta norma constitucional" (p. 4 del expediente).
} 
cimiento legal de las parejas homosexuales no es la igualación con las parejas heterosexuales, sino la protección de un bien contenido en esa clase de relación: porque hay algo valioso en ellas es que se reclama su reconocimiento legal. Para exigirlo, debe existir un bien que se desea proteger, y cuya desprotección frente a otro bien equivalente produce desigualdad y resulta injusta. Si la igualdad por sí misma (o la libertad sexual, o la privacidad, o el libre desarrollo de la personalidad) sirviera para justificar el matrimonio entre personas del mismo sexo, entonces no habría ninguna razón para limitarlo a dos personas. ${ }^{7}$

¿Por qué, entonces, reservar el matrimonio para un hombre y una mujer sería contrario al principio de igualdad? La respuesta sintetizada en los Vistos de la sentencia Rol № 1.881 es: "al negar a dos personas la posibilidad de contraer matrimonio y formar una familia, por su orientación sexual, la autoridad está atentando contra su libertad y derecho a ser consideradas iguales ante la sociedad y la ley, discriminándolas arbitrariamente pues, mientras las parejas heterosexuales pueden decidir entre contraer matrimonio o mantener relaciones de hecho, las homosexuales sólo pueden convivir, sin tener derecho a ningún tipo de protección legal". En el fondo del argumento descansa la idea que, respecto del matrimonio, las parejas heterosexuales y las parejas homosexuales representan un bien equivalente $y$, por lo tanto, excluir a las últimas del matrimonio es arbitrario.

Esta discusión sobre la constitucionalidad del artículo 102 del Código Civil manifiesta la existencia de un concepto distinto del matrimonio definido en la ley, que no considera el sexo como un elemento de su definición. ¿Cuál es esta definición? ¿De dónde emana? ¿Cuál es su autoridad? ¿Por qué la definición de matrimonio implícita en el voto del Ministro Vodanovic (punto 5 párrafo $4^{\circ}$, por ejemplo), es mejor, más válida, de mayor autoridad, etc. que la definición del artículo 102 del Código Civil? Resulta obvio que el resultado del juicio de igualdad que se haga del artículo 102 del Código Civil dependerá del concepto de matrimonio que tenga el juez.

\section{Dejemos por un rato de hablar de matrimonio}

La esencia de la cuestión sometida al conocimiento del Tribunal Constitucional es si la heterosexualidad es una condición del matrimonio que discrimina arbitrariamente a los homosexuales. La decisión de esta cuestión depende de qué se entienda por matrimonio. Si la heterosexualidad es un elemento esencial del concepto, entonces la discriminación no es arbitraria; si es un elemento accidental, entonces podría ser arbitraria (dependerá del valor de otros factores,

${ }^{7}$ Cfr. Sandel, Michael, Justicia. ¿Hacemos lo que debemos?, Traducción de Campos, Juan Pedro,Debate, Barcelona, 2011, p. 292. 
v. gr. culturales). Pero, planteado así el asunto, la discusión se convierte en una guerra de trincheras: qué sea matrimonio es, a fin de cuentas, una cuestión convencional (en este sentido, arbitraria) y, por lo tanto, entregada a los votos. El matrimonio es, desde cierta perspectiva, sólo una palabra, un término. Y la discusión sobre palabras es estéril. Lo que, en cambio, resulta valioso de discutir es si acaso existe alguna diferencia entre las parejas heterosexuales y las parejas homosexuales que justifique un estatuto jurídico diferente, con independencia del nombre que le pongamos a cada cual.

Prescindir del término matrimonio me parece útil en orden a transparentar la argumentación sobre su constitucionalidad. Porque es fácil perder el hilo del razonamiento, cuando se significan cosas distintas (aunque sólo sean parcialmente distintas) con el mismo término, sin que medie una advertencia. De hecho, en la sentencia ocurrió esto: en varios de los votos particulares se puede percibir la vacuidad conceptual con que se manipuló el término matrimonio. ${ }^{8}$ Algunos ejemplos de lo que se acaba de decir:

En el voto particular de los ministros Venegas, Navarro y Aróstica el siguiente párrafo: "podemos afirmar que el contrato de matrimonio definido en el artículo 102 del Código Civil (...) es, por su concepción misma, por su origen histórico social, por su fisonomía y por sus finalidades propias, una institución aplicable únicamente a las relaciones de parejas formadas por un hombre y una mujer..." (punto 12 del voto). Esta afirmación se asienta en un argumento circular, porque la conclusión ("el artículo 102 del Código Civil (...) es una institución aplicable únicamente a las relaciones de parejas formadas por un hombre y una mujer") es al mismo tiempo una de las premisas (la definición del artículo 102 del Código Civil lo hace aplicable únicamente a las relaciones de parejas formadas por un hombre y una mujer).

En el voto particular de los ministros Fernández, Carmona, Viera-Gallo y García, el siguiente párrafo: "Si el matrimonio hoy es entre un hombre y una mujer, no es porque lo diga o lo establezca la Constitución, sino la ley" (punto 10 del voto). Si lo que se quiere afirmar es el poder del legislador para decidir cómo se llaman las cosas, la sentencia es correcta. Pero sería un error entender esta afirmación en el sentido que el legislador puede decidir que la heterosexualidad no es una circunstancia cargada de significación jurídica. ${ }^{9}$ Aquí es oportuno recordar el aforismo "En Derecho las cosas son lo que son, y no lo que se dice que son ni lo que se pretende que sean".

\footnotetext{
${ }^{8}$ El problema de esto es el equívoco que se produce como consecuencia de un uso poco riguroso del concepto, porque pareciera que la realidad está condicionada por el nombre que se le ponga, y en este caso no es así.

${ }^{9}$ Tengo presente que el contexto de la cita comentada es la demostración de que la Constitución no opta por una determinada definición de matrimonio ni familia. Pero no creo hacerle traición utilizándola aquí.
} 
El Ministro Vodanovic expresa en su voto: "No hay duda que, para sus protagonistas, el matrimonio entre personas del mismo sexo expresa la plena realización de los valores de libertad, igualdad y dignidad humanas" (punto 2 del voto). ¿Qué significa matrimonio en este contexto? Porque evidentemente no es el matrimonio definido por el artículo 102 del Código Civil, toda vez que este excluye a los homosexuales. El término es el mismo (matrimonio), pero su significado es distinto: ¿cuándo se produjo este cambio?, ¿cuál es el origen de este distinto significado?, ¿cuál es su autoridad? No quiero discutir aquí el concepto de matrimonio, sino simplemente ilustrar la libertad con que se conserva el término pero se cambia su significado, sin justificarlo.

En cualquier caso, lo principal en este caso no es la discusión sobre qué es y qué no es matrimonio, porque fácilmente se convierte en una pura cuestión de nombres. Lo principal en este caso es decidir si entre las parejas heterosexuales y las homosexuales existe alguna diferencia que justifique un estatuto jurídico diferenciado.

\section{V. ¿HAY DifERenCias ReleVAntes O No?}

La justificación de un estatuto jurídico propio de las parejas heterosexuales (el artículo 102 del Código Civil es una de las expresiones de este estatuto) depende de la existencia de diferencias relevantes con otras clases de parejas. Para el caso de la sentencia que analizamos, la constitucionalidad del artículo 102 del Código Civil está condicionada a la demostración de una circunstancia que convierta en necesaria, idónea y proporcionada la exclusión de las parejas homosexuales del estatuto de las heterosexuales. ${ }^{10}$ Si hay diferencias relevantes entre ambos tipos de pareja, entonces la norma no es inconstitucional; $y$ viceversa.

a) No hay diferencias relevantes

Ya se vio que el recurso de protección plantea la cuestión en términos tales, que la desigualdad legal entre parejas heterosexuales y homosexuales aparece como arbitraria, porque no hay diferencias relevantes entre ambas. Si todos somos iguales en dignidad y derechos, ¿por qué sólo las parejas heterosexuales gozan de un estatuto jurídico que las reconoce y regula sus efectos? La injusticia de esta discriminación se nota en el mayor ámbito de libertad que tienen las parejas heterosexuales, porque "[e]n la práctica las parejas heterosexuales pueden decidir entre contraer matrimonio [o no]. Sin embargo, las parejas ho-

10 "... la igualdad (...) permite a la ley dar un trato diverso a las [personas] cuando existe un hecho diferenciador relevante entre distintas personas, apto y proporcionado para la diferencia jurídica que se extraiga" (punto 4 del voto particular del Presidente Bertelsen). Casi con la misma redacción el punto 8 del voto de Venegas, Navarro y Aróstica. 
mosexuales sólo pueden convivir pero sin gozar de ningún tipo de protección legal con la consiguiente desigualdad de derechos que ello conlleva". ${ }^{11}$

El Ministro Vodanovic, en su voto en contra, tampoco reconoce diferencias que justifiquen un trato desigual entre las parejas heterosexuales y homosexuales. El punto de partida de su argumento es la naturaleza absolutamente convencional del matrimonio: "En primer término, no debe desatenderse que la institución matrimonial, como cualquier otra, es una construcción social histórica". De aquí se sigue que la justificación de un estatuto diferenciado para las parejas homosexuales y heterosexuales depende de criterios esencialmente mutables en el tiempo: "Sus elementos esenciales [del matrimonio] no son, necesariamente, los de ayer ni serán forzosamente los de mañana". La procreación, como diferencia justificadora de la desigualdad ante la ley de las parejas heterosexuales y homosexuales, ha perdido fuerza en el matrimonio actual. Hoy prevalecen en la definición del matrimonio "las finalidades propias de la vida en común. El objetivo esencial, más bien, expresa fines de solidaridad, afecto y asistencia recíproca" (punto 5 del voto).

Para el Ministro Vodanovic no existen diferencias de significación jurídica entre los supuestos del matrimonio heterosexual y homosexual. Antes bien, la comparación entre ambos "establece que se trata de supuestos de hecho similares, pues en ambos casos se trata de la unión de dos personas plenamente capaces, que pretenden formar una comunidad de vida para construir un proyecto común" (punto 5 del voto). Evidentemente, a esta conclusión le sirve como premisa una determinada concepción del matrimonio, sólo parcialmente explicitada. ¿Cuál es la autoridad de esta definición? ¿Cuál es su fuente?

En el voto particular de los Ministros Fernández, Carmona, Viera-Gallo y García se puede percibir también una homologación entre las parejas heterosexuales y homosexuales, según la cual no se justificaría un estatuto jurídico distinto. Pero los términos de esta homologación son más sutiles que en el voto del Ministro Vodanovic, porque los argumentos se dirigen principalmente a demostrar que la igualdad exige un estatuto jurídico para las parejas homosexuales, y sólo secundariamente que ese estatuto debe ser el mismo que el de las parejas heterosexuales.

La inexistencia de diferencias de relevancia jurídica entre las dos clases de parejas, que sostienen los ministros en su voto particular, se expresa en palabras de la Corte Constitucional de Colombia: "no existen razones atendibles que permitan sostener que entre los miembros de la pareja del mismo sexo no cabe predicar el afecto, el respeto y la solidaridad que inspiran su proyecto de vida en común, con vocación de permanencia, o que esas condiciones personales

${ }^{11}$ Escrito de presentación de la demanda de protección, p. 4 del expediente. 
sólo merecen protección cuando se profesan entre personas de distinto sexo". ${ }^{12}$ El principio constitucional de igualdad exige que la ley reconozca y proteja a las parejas homosexuales, porque son una realidad que se ancla en derechos esenciales de la persona humana y que el Estado debe garantizar. Es injusto que en materia de libertad sexual, privacidad y libre desarrollo de la personalidad, las parejas heterosexuales gocen de reconocimiento legal y las homosexuales no. En el último punto del voto aclaran que, en todo caso, es deber del legislador (y no del Tribunal Constitucional) regular las uniones entre dos personas con independencia de su sexo, "incluso abriendo la institución matrimonial a personas del mismo sexo, si así lo estima conveniente" (punto 37 del voto).

b) Sí hay diferencias relevantes

El Presidente del Tribunal, Ministro Bertelsen, y la Ministra Peña, defendieron en sendos votos particulares la existencia de una diferencia relevante entre las parejas heterosexuales y homosexuales, que justificaría la existencia de un estatuto jurídico propio para las uniones entre un hombre y una mujer. Esta diferencia es la unión carnal que posibilita la procreación.

El Ministro Bertelsen en su voto particular reconoce, entre los fines del matrimonio definido en el artículo 102 del Código Civil, el de la procreación como un elemento que justifica un estatuto propio de las parejas heterosexuales. Porque "sólo la unión carnal entre ellas es la que, naturalmente, puede producir la procreación". De aquí que sea congruente una regulación que excluya a las parejas del mismo sexo (punto 6 del voto). Las diferencias entre el hombre y la mujer que posibilitan la procreación como fruto de la unión carnal o coito son motivo suficiente para definir un estatuto reservado para las parejas heterosexuales. Por esas diferencias entre el hombre y la mujer (que no existen entre los homosexuales), "no puede estimarse que [la definición del artículo 102 del Código Civil] constituye una diferencia arbitraria o caprichosa, sino fundamentada en las diferencias entre varón y mujer, que la ley, legítimamente, ha considerado y puede seguir considerando relevante para establecer que los contrayentes sólo pueden ser un hombre y una mujer" (punto 8 del voto).

El voto particular de la Ministra Peña también reconoce a la procreación una significación jurídica que justifica la existencia de una regulación propia de las parejas heterosexuales. Destaca la función decisiva que la procreación tiene para "la supervivencia y proyección de la sociedad a través del tiempo". El legislador no puede desconocer que la existencia de la sociedad depende de la procreación, que es la única forma de que nuevos individuos vengan al mundo. Y la procreación es un proceso "que sólo puede ser logrado a través de la unión de dos células, masculina y femenina, como las que se encuentran en el acto carnal entre un hombre y una mujer" (punto $3^{\circ}$ del voto). Luego, el acto carnal entre un hombre

${ }^{12}$ Citada en el punto 32 del voto particular. 
y una mujer es un hecho relevante que amerita un reconocimiento jurídico como el que le brinda el artículo 102 del Código Civil.

\section{LA POSIBILIDAD DEL COITO JUSTIFICA UN ESTATUTO JURÍDICO SEPARADO}

Sería un error entender el matrimonio heterosexual como una institución cuya regulación jurídica se justifica única o principalmente por el acto sexual procreativo. También sería un error creer que es el coito lo que hace valioso el matrimonio heterosexual como unión entre dos personas. El coito es la forma en que se cumple naturalmente la función biológica de la reproducción sexual. "En el coito, y no en otras formas de contacto sexual, los cuerpos de un hombre y una mujer se coordinan a través de sus órganos sexuales para realizar el fin biológico de la reproducción". ${ }^{13}$

La unión orgánica entre los cuerpos de un hombre y una mujer es la característica que específica una clase de pareja que, junto a otras características, responde a la definición del artículo 102 del Código Civil. El coito es una característica que especifica a las parejas heterosexuales de las parejas homosexuales. La cuestión es si esta característica justifica un estatuto jurídico propio y excluyente de las parejas homosexuales (y de cualquier otra clase de unión).

El coito es el primer paso del proceso procreativo; nuevos seres humanos comienzan a existir como resultado de este acto. Y con la existencia de un nuevo ser, se crean nuevas relaciones interpersonales (entre los padres y el hijo) y se modifican otras (de los padres entre sí). Estas nuevas situaciones no son irrelevantes desde la perspectiva del orden social. Las obligaciones morales que nacen a partir de la existencia de un nuevo ser humano, tienen una dimensión social relevante y, por eso, exigen un reconocimiento legal. La regulación legal de esta dinámica y su estructura es lo que tradicionalmente se ha llamado matrimonio. Puesto que la unión corporal que puede dar origen a un nuevo ser humano es exclusivamente entre un hombre y una mujer, la exclusión de las parejas homosexuales del marco regulatorio no es arbitraria. Esto es lo mismo que afirmar la conveniencia de un estatuto jurídico propio y específico para las parejas heterosexuales. Por el mismo motivo, se justifica un estatuto jurídico distinto para cada una de las dos clases de pareja. ${ }^{14}$

\footnotetext{
${ }^{13}$ Girgis, Sherif, George, Robert; Anderson, Ryan, "What is Marriage?", Harvard Journal of Law \& Public Policy, Vol. 34, pp. 245-287. 254. La traducción es mía.

${ }^{14}$ La existencia de técnicas de reproducción asistida y la adopción no anulan la relevancia diferenciadora que tiene el coito, porque este no es sustituido por ellas. La multiplicación de posibilidades para originar una nueva vida humana amplía el número de situaciones que el Derecho debe atender, pero no borra la desigualdad original entre parejas heterosexuales y homosexuales: los homosexuales no pueden copular. La perspectiva para analizar esta materia no es la idoneidad de la pareja para criar niños, sino la idoneidad de la pareja para concebirlos con sus propios cuerpos (GIRGIS; Anderson, "What is Marriage?", cit. nota n. 13, pp. 267 y 268 ).
} 
“La constitucionalidad del artículo 102 del Código Civil ante el tribunal COnStitucional. Comentario CRítICO DEL REQUERIMIENTO DE INAPLICABILIDAD FALLADO EN LA SENTENCIA Rol № 1.881, DE 3 DE NOVIEMBRE DE 2011"

\section{El PROBLEMA DEL RECONOCIMIENTO LEGAL DE LAS PAREJAS HOMOSEXUALES}

Admitir que existen diferencias relevantes desde el punto de vista de su regulación jurídica, entre las parejas heterosexuales y las parejas homosexuales, no implica que las parejas homosexuales deban ser reguladas jurídicamente (por supuesto, tampoco se sigue que no deban serlo).

Es fácil incurrir en una confusión en este punto, porque la demanda de protección desde donde se promovió el requerimiento de inaplicabilidad -y algunos votos particulares- identifica el matrimonio con la única forma de reconocimiento y protección legal de las parejas, cuando en realidad son dos cosas distintas. Como consecuencia de esta identificación, se superponen el supuesto carácter discriminatorio del artículo 102 del Código Civil con la ausencia de reconocimiento y protección de las parejas homosexuales. Pero son dos cosas distintas. Afirmar la constitucionalidad del artículo 102 del Código Civil no implica necesariamente negar el reconocimiento legal de las parejas homosexuales. Son dos cuestiones distintas que deben ser tratadas separadamente.

El voto particular firmado por los ministros Navarro, Venegas y Aróstica, y el otro firmado por los ministros Fernández, Viera-Gallo, Carmona y García, reconocen que la constitucionalidad del artículo 102 del Código Civil es una cuestión distinta del reconocimiento legal de las parejas homosexuales. En el primer caso, un párrafo elocuente: "Si bien nuestro voto descarta la inconstitucionalidad del artículo 102 del Código Civil, no afirma ni niega que la Constitución acepte, promueva, impida o condene la posibilidad de que parejas homosexuales puedan convivir y realizar una vida afectiva en común protegida por el ordenamiento jurídico, pues corresponde al Legislador, y no a esta Magistratura Constitucional, dar forma a las nuevas instituciones legales que vengan a dar satisfacción a las necesidades de la marcha de la sociedad, teniendo en cuenta las mutaciones que ella experimenta en su constante evolución" (punto 14 del voto). En el segundo caso, los ministros firmantes declaran que la discriminación arbitraria que afecta a las parejas homosexuales consiste en la ausencia de una regulación legal que reconozca la proyección pública de esta clase de uniones (cfr. punto 28 del voto). Pero esta inconstitucionalidad no se subsana necesariamente reformulando la definición del artículo 102 del Código Civil. La modificación de esta definición legal podría ser una forma de reparar la injusta desigualdad entre las parejas heterosexuales y homosexuales, pero no la única. Esto se infiere, por ejemplo, de la alternativa reconocida en el número 35 del voto ("Que para efectuar tal modificación [del artículo 102 del Código Civil] o para regular la convivencia de personas del mismo sexo..."); también se infiere de la alternativa propuesta en el número 37 del voto: compete al Parlamento regular "alguna forma de unión civil entre dos personas, 
independientemente de su orientación sexual, e incluso abriendo la institución matrimonial a personas del mismo sexo, si así lo estima conveniente".$^{15}$

El voto en contra del Ministro Vodanovic, en cambio, identifica la plena igualdad ante la ley de las parejas heterosexuales y homosexuales, con la ampliación del concepto de matrimonio a las personas del mismo sexo. El reconocimiento legal de las uniones homosexuales es, sin duda, un avance en la línea de la igualdad, pero "no borra la discriminación denunciada. Como se ha reiterado, ésta se produce por la exclusión del matrimonio" (punto 6 del voto). En la última conclusión de su voto, el Ministro destaca: "La demanda de las parejas del mismo sexo no persigue que se les confiera un tratamiento especial, sino simplemente poder participar de los beneficios de la vida en sociedad, accediendo en términos de igualdad a una institución considerada indispensable para el desarrollo de los propios planes de vida, como es el matrimonio. Por estas razones, el artículo 102 del Código Civil debe ser declarado inconstitucional" (punto 7 de las Conclusiones del voto).

\section{CONCLUSIONES}

La sentencia 1881-INA-10 del Tribunal Constitucional da pistas valiosas para juzgar la constitucionalidad del matrimonio heterosexual, desde la perspectiva del principio de igualdad. Esto aunque las pistas se hallen en los votos particulares suscritos por los distintos ministros del Tribunal. Entre las cuestiones que podrían señalarse, destaco, en primer lugar, la distinción entre el problema de la constitucionalidad del artículo 102 del Código Civil y el problema de la regulación legal de las parejas homosexuales. Son dos problemas distintos que deben tratarse separadamente, porque lo contrario enturbia la discusión. En segundo lugar, el cuidado con que debe utilizarse la palabra matrimonio, para no incurrir en equívocos o facilitar la construcción de argumentos falaces. De aquí que sea preferible prescindir del término para fijarse en el contenido de las realidades que se están juzgando. En tercer lugar, la necesidad de justificar racionalmente la existencia o inexistencia de un elemento diferenciador entre las parejas heterosexuales y homosexuales, que por su relevancia la ley deba considerar para definir el marco regulatorio. En este punto, la piedra de toque es el acto procreativo: ¿constituye éste una diferencia que justifique un estatuto jurídico distinto para las parejas heterosexuales y las homosexuales?

${ }^{15}$ Las cursivas son mías. 